\title{
Overexpression of plasminogen activators in the nucleus accumbens enhances cocaine-, amphetamine- and morphine-induced reward and behavioral sensitization
}

\author{
A. Bahi and J.-L. Dreyer* \\ Institute of Biochemistry, University of Fribourg, Fribourg, \\ Switzerland \\ ${ }^{*}$ Corresponding author: J.-L. Dreyer, Institute of Biochemistry, \\ University of Fribourg, Rue du Musée 5, CH-1700 Fribourg, \\ Switzerland.E-mail: jean-luc.dreyer@unifr.ch
}

\begin{abstract}
Urokinase-type plasminogen activator (uPA) and tissuetype plasminogen activator (tPA) are extracellular proteases that play a role in synaptic plasticity and remodeling. Psychostimulants induce both tPA and uPA in acute and chronic drug delivery, but cocaine induces preferentially uPA, whereas morphine and amphetamine induce preferentially tPA. Specific doxycline-regulatable lentiviruses expressing these extracellular proteases have been prepared and stereotaxically injected into the nucleus accumbens. We show that tPA-overexpressing animals show greater locomotor activity and behavioral sensitization upon morphine and amphetamine treatments. These effects could be fully suppressed by doxycycline or when tPA had been silenced using small interfering RNAs (siRNAs)-expressing lentiviruses. Furthermore, animals infected with lentiviruses expressing uPA show enhanced conditional place preference for cocaine compared with tPA-overexpressing animals. In contrast, tPA-overexpressing animals when administered amphetamine or morphine showed greater place preference compared with uPA-overexpressing animals. The effects are suppressed when tPA has been silenced using specific siRNAs-expressing vectors. Tissue-type plasminogen activator and uPA possibly induce distinct behaviors, which may be interpreted according to their differential pattern of activation and downstream targets. Taken together, these data add further evidence for a significant function of extracellular proteases TPA and UPA in addiction and suggest a differential role of plasminogen activators in this context.
\end{abstract}

Keywords: Activator, addiction, cocaine, drugs of abuse, in vivo gene transfer, lentivirus, plasminogen, plasticity, RNA interference, serine proteases, siRNA
Activity-dependent synaptic plasticity and remodeling of the mesolimbic dopaminergic system play a crucial role in the development of drug dependence (Nestler 2001). Changes in the synaptic morphology may be due, at least in part, to local extracellular proteolysis of cell adhesion and extracellular matrix molecules. Some extracellular serine proteases of the plasminogen activator family may modulate synaptic adhesion and associate with long-term potentiation and learning behavior. Tissue-type plasminogen activator (tPA) and urokinase-type (UPA) plasminogen activator are serine proteases, which both activate plasminogen into plasmin. Tissue-type plasminogen activator is abundantly expressed in the central nervous system (Bu et al. 1994; Davies et al. 1998; Hayden \& Seeds 1996; Oian et al. 1993; Seeds et al. 1995) and participates in neurite outgrowth and neuronal development by cleaving proteins of the extracellular matrix and potentially forming a path for extending process (Jacovina et al. 2001; Wu et al. 2000). Tissue-type plasminogen activator contributes to the regulation of numerous aspects of synaptic plasticity and remodeling. It is synthesized by neurons of most brain regions and contributes also to adult central nervous system physiology, inducing neuronal plasticity and synaptic reorganization (Nakagami et al. 2000; Sappino et al. 1993). Tissue-type plasminogen activator is also induced in the brain by electrical activity leading to synaptic remodeling (Ripley et al. 1999). The role of uPA in the brain has also been described, but its function still remains poorly characterized. Its involvement in learning-related plasticity has been established in knockout mice, but these mice were impaired in tasks of spatial, olfactory and taste-aversion learning while showing normal sensory and motor capabilities (Meiri et al. 1994).

A single morphine treatment induced tPA mRNA and protein expression in neuronal cells of the nucleus accumbens (NAc) (Nagai et al. 2004). Morphine-induced conditioned place preference and hyperlocomotion were significantly reduced in tPA-deficient (tPA knockout mice) and plasminogendeficient (plg knockout mice) mice, being accompanied by a loss of morphine-induced dopamine release in the NAc. The defect of both morphine-induced dopamine release and hyperlocomotion in tPA knockout mice was reversed by microinjections of either exogenous tPA or plasmin into the NAc. These findings suggest that the tPA-plasmin system is involved in the rewarding effects of morphine, by acutely regulating morphine-induced dopamine release in the NAc (Nagai et al. 2004). Furthermore, tPA is also induced in the prefrontal cortex by acute cocaine and appears to play a 
specific role either in retention of information between sessions or in behavioral inhibition in cocaine self-administration. In addition, amphetamine also induces expression of tPA in prefrontal cortex and has been implicated in both behavioral sensitization to psychostimulants, and in drug self-administration (Schenk \& Snow 1994). Chronic but not acute methamphetamine treatment dose dependently induced tPA mRNA expression in the frontal cortex, NAc, striatum and hippocampus. In the NAc, this effect could be blocked by pretreatment with dopamine D1 and D2 receptor antagonists, indicating that IPA is involved in rewarding effects as well as sensitization of the locomotor-stimulating effect of metamphetamine (Nagai et al. 2005a, 2005b).

In previous studies, we showed that UPA is strongly induced upon cocaine delivery (Bahi et al. 2004a, 2006). Cocaine induced two- to sixfold increase of uPA mRNA in the mesolimbic dopaminergic pathway, including the ventral tegmental area (VTA), the NAc and the hippocampus (Bahi et al. 2004a). Also local overexpression of uPA in these brain area, by stereotaxic injection of a doxycycline-regulated UPAexpressing lentivirus (LV-uPA), showed almost a 6- to 10-fold increase in locomotor activity after cocaine treatment compared with saline injection, an effect completely abolished with doxycycline or when a dominant-negative form of UPAexpressing lentivirus had been delivered (Bahi et al. 2004a, 2006). Furthermore, using lentiviruses expressing small interfering RNAs (siRNAs) targeted against uPA mRNA, we clearly established that UPA induces strong behavioral changes associated with cocaine delivery (Bahi et al. 2006).

In the present paper, we compare behavioral changes induced upon uPA and tPA expression in the NAc on cocaine-, morphine- or amphetamine-induced behaviors. Clearly, UPA and tPA induce distinct behaviors, which may be interpreted according to their differential pattern of activation and downstream targets. Our data add further evidence for a significant function of extracellular proteases tPA and UPA in addiction and drug-related synaptic plasticity and suggest a differential role of plasminogen activators in this context.

\section{Materials and methods}

\section{Animal work}

Animals used in this experiment were male Wistar rats weighing 200 $250 \mathrm{~g}$. All animal experiments were carried out in accordance with the guidelines and regulations for Animal Experimentation, BAG, Bern, Switzerland. All rats were naive and were used in a single experiment only. They were housed in threes in clear plastic cages with wire grid lids. Access to food and water was unrestricted. The animals were kept in the animal facility maintained on a 12-h light:12-h dark cycle (light off at 7 a.m.).

\section{Construction of tPA-expressing lentivirus}

Using total RNA from rat brain cocaine treated, the tPA complementary (cDNA) was amplified and 6 His-tagged by reverse transcription using M-MLV-RT (Invitrogen, Basel, Switzerland) following the manufacturer's instructions. We performed polymerase chain reaction (PCR) amplification using this set of primers specific for rat tPA (forward primer with BamHI: CGC GGG ATC CAT GAA GGG AGA GCT GTT GTG C; reverse primer with Xhol: GCC GCT CGA GTT AAT
GAT GAT GAT GAT GAT GTT GCT TCA TGT TGT CTT GAA T. restriction enzyme sites are in bold). The cDNA was then digested with $\mathrm{BamHI}$ and $\mathrm{XhOl}$ and cloned into similar sites in the lentiviral system transfer vector pTK431. A control vector construct, in which green fluorescent protein (GFP) expression is regulated by a tetracycline-inducible promoter, was generated by cloning a BamHI/Bg/lI DNA fragment containing the GFP gene into a BamHI site in pTK431 (Bahi et al. 2004a, 2004b, 2005a, 2005b, 2006). Besides, LV-uPA and LV-uPA-Mut production were performed as described previously (Bahi et al. 2004a, 2006)

\section{Construction of tPA-specific siRNAs-expressing lentiviral vectors}

To silence TPA expression in vitro and in vivo, three targets were designed, according to the rat tPA mRNA sequence (GenBank accession no. M23697). The following targets within the tPA sequence were selected: first target, 2-25; second target, 16501673; and third target, 733-756. To each oligo, an Xho/ restriction site was $3^{\prime}$ added. Using the pSilencer 1.0-U6 (Ambion, Huntington, UK) as a template and an U6 promoter-specific forward primer containing BamHI (In bold) restriction site GCG GAT CCC GCT CTA GAA CTA GTG C, each siRNA target was added to the mouse U6 promoter by PCR (each target contains a 3 '-specific U6 promoter-specific primer). The PCR conditions were highly drastic to avoid mutations within the targets. The following PCR program was performed: 120 seconds at $94^{\circ} \mathrm{C}$ (initial denaturation) followed by $94^{\circ} \mathrm{C}$ for 45 seconds, $64^{\circ} \mathrm{C}$ for 45 seconds and $72^{\circ} \mathrm{C}$ for 45 seconds, repeated for 35 cycles. The PCR reaction contains $4 \%$ dimethyl sulfoxide (Sigma, Buchs, Switzerland). The PCR product was digested with $\mathrm{BamH/}$ and Xhol, cloned into similar sites in PTK431 and sequenced to verify the integrity of each construct.

After cloning and sequencing, all plasmids were $\mathrm{CsCl}_{2}$ purified. Vesicular stomatitis virus $\mathrm{G}$ pseudotyped lentiviruses were produced by the transient calcium phosphate cotransfection of HEK293T cells with $\mathrm{pTKs}$ vectors together with pMDG-VSV-G and $\mathrm{p} \Delta \mathrm{NRF}$ as previously described (Bahi et al. 2004a, 2004b, 2005a, 2005b, 2006). Lentiviral vector quantifications were performed according to the p24 enzyme-linked immunosorbent assay (KPL, Gaithersburg, MD, USA) in accordance with the manufacturer's instructions. Besides, uPA-specific siRNAs-expressing lentiviral vectors (LV-uPA-siRNAs) (for silencing uPA) have been described previously (Bahi et al. 2006).

\section{In vitro experiments}

For doxycycline regulation, HEK293T cells were infected with 0, 3, 6 or $9 \mu \mathrm{l}$ from viral stock of tPA-expressing lentivirus (LV-tPA) together with $4 \mu \mathrm{l}$ of LV-uPA (Bahi et al. 2004a, 2006). Culture medium was supplemented with $30 \mathrm{ng} / \mathrm{ml}$ of doxycycline. After $72 \mathrm{~h}$, culture medium was removed and cells were used for total RNA extraction.

To test the knock-down effect of tPA expression with tPA-specific siRNAs-expressing lentiviral vectors (LV-tPA-siRNAs) in vitro, cells were infected with $3 \mu \mathrm{l}$ of LV-tPA, together with $4 \mu \mathrm{l}$ of LV-uPA; knockdown was performed by adding either $2 \mu \mathrm{l}$ of LV-tPA-siRNA1, $2 \mu \mathrm{l}$ of LV-tPA-siRNA2, $2 \mu \mathrm{l}$ of LV-tPA-siRNA3 or $2 \mu \mathrm{l}$ of the three targets together. After $72 \mathrm{~h}$, culture medium was removed and cells were used for total RNA extraction.

\section{Real-time PCR and tPA mRNA quantification}

Total RNA was extracted from the HEK293T cells using Trizol reagent (Invitrogen) according to the manufacturer's instructions. RNA was quantified by spectrophotometry, and its integrity was verified by agarose gel electrophoresis and visualized with ethidium bromide staining. First-strand cDNA was generated from $4 \mathrm{mg}$ of total RNA and oligo(dT ${ }_{12-18}$ ) primer with the M-MLV-RT (Invitrogen) in a total volume of $20 \mu \mathrm{l}$ according to the manufacturer's protocol. To quantify the tPA mRNA level, quantitative real-time PCR was performed using this set of primers specific to rat IPA CDNA (forward primer: AAG GAG GCT CAC GTC AGA CTG TA; reverse primer: CCT GCA CAC AGC ATG 
TTG CT). For control, uPA and glyceraldehyde-phosphate dehydrogenase (GAPDH) sets of primers were described previously (Bahi et al. 2004a, 2006).

The quantification was performed using the real-time PCR iCycler (BioRad, Reinach, Switzerland). For PCR, $5 \mu \mathrm{l}$ CDNA preparation, 0.5 $\mathrm{mM}$ of forward and reverse primers and $10 \mu \mathrm{l}$ of IQ SYBR Green Supermix (Biorad) in a total volume of $20 \mu \mathrm{l}$ were applied. The following PCR program was performed: $3 \mathrm{~min}$ at $95^{\circ} \mathrm{C}$ (initial denaturation); $20^{\circ} \mathrm{C} /$ second temperature transition rate up to $95^{\circ} \mathrm{C}$ for 45 seconds, 45 seconds $62^{\circ} \mathrm{C}$, repeated for 40 times (amplification). The PCR reaction was evaluated by melting curve analysis following the manufacturer's instructions and checking the PCR products on $2 \%$ agarose gel.

The PCR cycle number at which each assay target reached the threshold detection line was determined (Ct value). Complementary DNA samples were assayed on at least three dilutions to check for assay reliability using duplicate assay on each dilution. The deltaCt for each candidate was calculated as deltaCt $=[\mathrm{Ct}$ (tPA or uPA) $-\mathrm{Ct}$ (GAPDH)]. The relative abundance of tPA and uPA transcripts can be calculated as the ratio between treated control samples (Bahi et al. 2004a, 2004b, 2005a, 2005b, 2006).

\section{Stereotaxic surgeries}

Lentiviral injections into the NAc were performed according to the previous publications (Bahi et al. 2004a, 2004b, 2005a, 2005b, 2006). Briefly, rats were anesthetized with a mix of ketamine/ xylazine $(100 \mathrm{mg} / \mathrm{kg} / 10 \mathrm{mg} / \mathrm{kg}$, intraperitoneal [i.p.]) and placed in a stereotaxic apparatus. Using a 10- $\mu$ l Hamilton syringe, $4 \mu \mathrm{l}$ of concentrated lentiviral stocks were injected into the NAc $(+1.4 \mathrm{~mm}$ anteroposterior: $\pm 1.6 \mathrm{~mm}$ mediolateral from bregma and -6.8 dorsoventral from the skull; Paxinos \& Watson 1998). Following 7 days recovery from the operation, rats were used for behavioral studies.

\section{Drug treatment}

For tPA mRNA expression, the protocols used were described previously (Bahi \& Dreyer 2005). Amphetamine, morphine and cocaine hydrochloride (Sigma) were dissolved in $0.9 \%$ physiological saline. For single-injection treatments, rats were given a subcutaneous injection of morphine $(10 \mathrm{mg} / \mathrm{kg})$, amphetamine $(2 \mathrm{mg} / \mathrm{kg}$, i.p.) or cocaine $(20 \mathrm{mg} / \mathrm{kg}$, i.p.).

\section{Behavioral experiments}

For acute effects, rats were injected saline $(1 \mathrm{ml} / \mathrm{kg})$ or drugs (either morphine $10 \mathrm{mg} / \mathrm{kg}$ subcutaneously [s.c.], amphetamine $2 \mathrm{mg} / \mathrm{kg}$, i.p. or cocaine $20 \mathrm{mg} / \mathrm{kg}$, i.p.) on day 1, and the locomotor activity was measured for $180 \mathrm{~min}$ (morphine-injected animals) or 60 min (cocaineand amphetamine-injected rats).

For evaluation of sensitization effects, rats were injected drugs (morphine $10 \mathrm{mg} / \mathrm{kg}$, amphetamine $2 \mathrm{mg} / \mathrm{kg}$, i.p., or cocaine $20 \mathrm{mg} /$ $\mathrm{kg}$, i.p.) once per day for 24 days from days 2 to 24 , and drug-induced locomotor activity was measured every day for $180 \mathrm{~min}$ (morphineinjected animals) or 60 min (cocaine- and amphetamine-injected rats). Over this period of 24 days, rats were given normal water supplemented with $5 \%$ sucrose during the first 10 days (days $1-10$ ) enabling to fully express the genes of interest. Then, during a second session (days 11-17), rats were fed $0.02 \%$ doxycycline in the drinking water ( $5 \%$ of sucrose) to inhibit expression of ectopic tPA, UPA or GFP. Thereafter, in a third session (days 18-24), ectopic gene expression was switched back by removing doxycycline from the drinking water ( $5 \%$ sucrose). During these sessions, drug was daily injected. Finally, drug was withdrawn for 2 weeks, and then animals were challenged with one single injection of drug (same doses) and the behaviors were measured (over $180 \mathrm{~min}$ for morphine-injected animals or over 60 min for cocaine- and amphetamine-injected rats) (Bahi et al. 2004a, 2004b, 2005a, 2005b, 2006).
Conditioned place preference was performed as previously described (Bahi et al. 2006). Briefly, in the preconditioning period, the rat was allowed to move freely between two boxes (consisting of either wire grid or mesh floor) daily for 20 min for 3 days (days 1-3). On day 3 , the amount of time spent in each chamber was monitored and used to assess unconditioned preferences. Thereafter, during the conditioning phase, the rat was injected on days 4,6 and 8 either morphine (10 mg/kg), amphetamine (2 mg/kg, i.p.) or cocaine $(20 \mathrm{mg} /$ $\mathrm{kg}$, i.p.) and immediately confined in the floor-mesh box for $20 \mathrm{~min}$. On days 5,7 and 9, the rat was injected saline $(1 \mathrm{ml} / \mathrm{kg})$ and placed in the wire grid chamber for $20 \mathrm{~min}$. During the conditioning phase, chambers were never communicating and they were blocked by a guillotine door. On day 10, the postconditioning conditioned place preference test was performed without drug treatment. Animals were placed between the two chambers with the guillotine door removed and allowed free access to the entire set up. The time the rat spent in each chamber was measured for $20 \mathrm{~min}$. Drug-induced place preference behavior was expressed by post versus pre, which was calculated as: [(postvalue) - (prevalue)], where post- and prevalues were the difference in time spent at the drug-conditioning site in the postconditioning and preconditioning, periods, respectively.

\section{Gel zymography}

For sodium dodecyl sulphate-polyacrylamide gel electrophoresis (SDS-PAGE) zymography, rats were killed at the end of locomotor activity monitoring, brains quickly removed and NAc regions rapidly dissected and used for protein extraction. The tissue was homogenized in $0.5 \mathrm{ml}$ of cold extraction buffer that contained $50 \mathrm{~mm}$ Tris$\mathrm{HCl}, \mathrm{pH} 6.8,0.05 \%$ Triton-X-100 and $2 \mathrm{~mm}$ ethylenediaminetetraacetic acid. The tissue homogenate was incubated for $15 \mathrm{~min}$ on ice and vortexed. Then, the homogenate was centrifuged for $20 \mathrm{~min}$ at 10 $000 \mathrm{~g}$ and the supernatant collected and stored at $-80^{\circ} \mathrm{C}$. Protein concentrations were measured using the Bradford method. Equal amounts of protein extracts $(10 \mu \mathrm{g})$ were mixed with nonreducing SDS-PAGE sample buffer (62.4 mm Tris, pH 6.8, 20\% glycerol, 2\% SDS) and run in a $10 \%$ SDS-PAGE gel containing $0.1 \%$ casein (Sigma) and $12 \mathrm{mU} / \mathrm{ml}$ plasminogen (Calbiochem, Switzerland). After electrophoresis, the gel was washed four times for $30 \mathrm{~min}$ with $100 \mathrm{~mm}$ Tris$\mathrm{HCl} \mathrm{pH} \mathrm{8.0,50} \mathrm{mm} \mathrm{MgCl} 2$ and 2.5\% Triton-X-100 solution. The gel was then incubated overnight in $100 \mathrm{~mm}$ Tris- $\mathrm{HCl}, \mathrm{pH} 8.1$, and $15 \mathrm{~mm}$ $\mathrm{MgCl}_{2}$ solution at $37^{\circ} \mathrm{C}$, stained with Coomassie brilliant blue (Sigma) and destained with solution containing 35\% methanol, 7\% acetic acid. Urokinase-type plasminogen activator and tPA activity were then observed in the gel as light bands against a dark background.

\section{Immunohistochemistry}

Brain section staining was performed according to previously published procedures (Bahi et al. 2004a). Briefly, rat brains were rapidly removed and frozen in isopentane at $-30^{\circ} \mathrm{C}$ for 3 min and kept at $25^{\circ} \mathrm{C}$. Coronal sections were cut at $14 \mu \mathrm{m}$ in a cryostat (Leitz, Lucern, Switzerland), placed on gelatinized glass slides and air dried at room temperature for $20 \mathrm{~min}$. Antigens were localized using the avidinbiotin-peroxidase technique. Slices were fixed in $4 \%$ paraformaldehyde for $15 \mathrm{~min}$ and washed three times with $1 \times$ phosphate-buffered saline (PBS). Endogenous peroxidase activity was quenched with $2 \%$ hydrogen peroxide in water $\left(\mathrm{H}_{2} \mathrm{O}_{2}\right)$ for $40 \mathrm{~min}$ at room temperature. Non-specific binding was blocked for $30 \mathrm{~min}$ at room temperature in $1 \times$ PBS containing $1 \%$ bovine serum albumin, $1 \%$ Triton-X-100 and $3 \%$ normal goat serum. Sections were then rinsed and incubated overnight with mouse anti-histidine antibody (MCA1396, 1:12 000; Serotec, Düsseldorf, Germany) diluted in $1 \times$ PBS containing $1 \%$ Triton-X-100 and $1 \%$ normal goat serum. Sections were then washed three times with $1 \times \mathrm{PBS}$ and incubated with the biotinylated secondary antibody (goat anti-mouse immunoglobulin G, 1: 500; Vector Laboratories, Burlingame, CA, USA) for $45 \mathrm{~min}$ at room temperature. Sections were rinsed three times for $5 \mathrm{~min}$ in $1 \times$ PBS at room temperature, followed by incubation in avidin-biotin complex (Vector Laboratories) in $1 \times$ PBS solution. After three rinses in $1 \times$ PBS, all sections were developed in $0.025 \% 3-3^{\prime}$ diaminobenzidine tetrahydrochloride plus $0.02 \% \mathrm{H}_{2} \mathrm{O}_{2}$ for $10-15 \mathrm{~min}$. Sections were then 
dehydrated, mounted in permanent medium (Eukitt) and examined with a Zeiss light microscope.

\section{Statistical analysis}

All data were expressed as the mean \pm SEM and analyzed using SPSS v11 software. In the analysis of tPA mRNA expression, place conditioning and locomotor activity test, statistical analysis was performed using an analysis of variance (ANOVA), followed by the Tuckey test when $F$ ratios were significant $(P<0.05)$. Statistical differences between groups were determined with the Mann-Whitney $U$ test. In the analysis of the time-course for chronic locomotor sensitization, statistical differences between groups were determined by ANOVA with repeated measures.

\section{Results}

Previous studies have shown that cocaine induces UPA in different brain area upon different paradigms of drug administration (Bahi et al. 2004a). Under similar conditions, cocaine induced tPA mainly in chronic paradigms (Fig. 1). Under chronic drug delivery, a 4.8-fold mRNA increase is observed in the NAc ( $P<0.05$ compared with saline) and a 2.2-fold increase was further observed in the VTA. Changes in cocaine-mediated tPA mRNA induction were also very significant in the striatum $(4.5$-fold increase, $P<0.05)$ and in the hippocampus (3.3-fold increase, $P<0.05$ ). Acute treatment, however, produced only slight but significant changes in the NAc and the striatum (1.5- and 1.2-fold increase, respectively), whereas in the other brain regions, tPA was not induced, in contrast with observation reported under similar conditions for uPA (Bahi et al. 2004a).

Lentiviruses expressing tPA or siRNAs targeted against tPA have been prepared and tested in vitro in HEK293Tinfected cells (Fig. 2). Expression of tPA is titer dependent and doxycycline regulatable. Coinfection of HEK293T cells with various titers of LV-tPA and fixed levels of the doxycyclineregulatable LV-uPA (Bahi et al. 2004a) induces titer-dependent expression of tPA mRNA but does not influence expression of the related uPA mRNA (Fig. 2).

HEK293T cells were coinfected with LV-tPA at fixed levels and with three different LV-siRNAs, either alone or combined (Fig. 3). As a control, LV-uPA was also coinfected in all experiments. Control cells were infected with LV-uPA together with LV-tPA (Fig. 3). As a result, LV-siRNAs had no effects on uPA expression but strongly affected the expres-

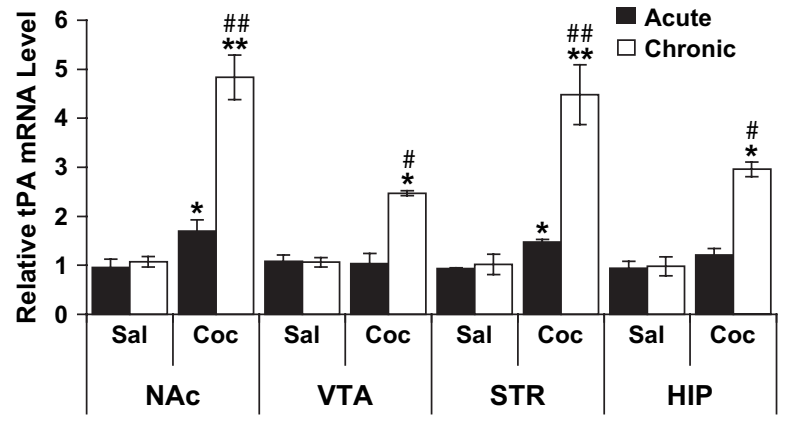

Figure 1: Changes in tPA mRNA expression after acute and chronic cocaine injection in the brain. Rats were injected once (acute) or during 2 weeks once a day (chronic) with $20 \mathrm{mg} / \mathrm{kg}$ i.p. of cocaine and killed $24 \mathrm{~h}$ after the last injection. The different brain areas were dissected out, total RNA was extracted and TPA transcripts were quantified by mean of real-time PCR using specific primers. Values indicate means \pm SEM. ${ }^{*} P<0.01$ and ${ }^{*} P<0.005$ compared with saline-treated groups. ${ }^{\#} P<0.01$ and ${ }^{\# \#} P<0.005$ compared with acute cocaine-treated groups. Coc, cocaine $20 \mathrm{mg} / \mathrm{kg}$; HIP, hippocampus; Sal, saline $1 \mathrm{ml} / \mathrm{kg}$; STR, striatum.

sion of tPA, which was diminished to $78 \%, 43 \%$ and $62 \%$, respectively, in presence of LV-siRNA1, LV-siRNA2 or LVsiRNA3 alone. Furthermore, when combined together, the mix of LV-siRNAs induced a $92 \%$ decrease in tPA mRNA $(P<$ 0.05 compared with control cells), whereas uPA mRNA remains unaffected.

\section{In vivo studies}

Using these molecular tools and the tools previously described (Bahi et al. 2004a, 2006), several groups of animals were prepared, stereotaxically injecting lentiviruses into the NAc and their behavioral activity in response to drugs was measured. In an initial experiment (Fig. 4), one set of animals was fed doxycycline, the other animals were fed without doxycycline all through the experiments. Control groups were injected LV-GFP into the NAc.

\section{Effects of cocaine}

Animals overexpressing tPA in the NAc show a 1.5-fold increase in locomotor activity compared with GFP controls
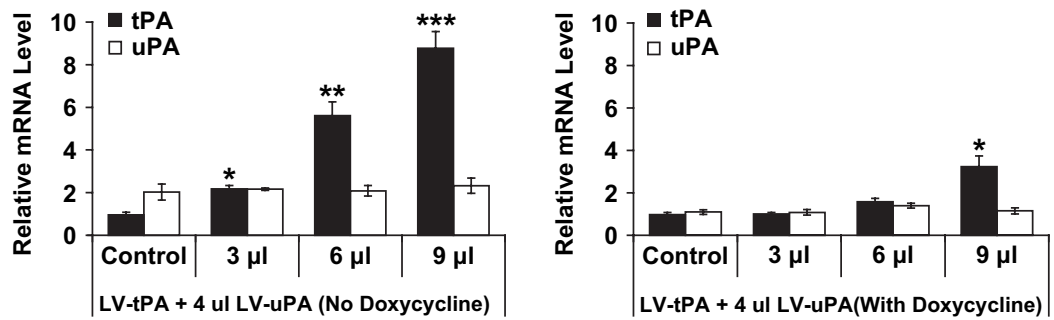

Figure 2: In vitro manipulation of LV-tPA in HEK293T cells and quantification of tPA mRNA expression. HEK293T cells were coinfected with $0,3,6$ or $9 \mu$ l of LV-tPA together with $4 \mu$ l of LV-uPA-His6. Culture medium was supplemented with or without doxycycline $(30 \mathrm{ng} / \mathrm{ml}$ ). After $72 \mathrm{~h}$, culture medium was removed, total RNA was extracted and transcripts were quantified by mean of real-time PCR using specific primers. Values indicate means \pm SEM. ${ }^{*} P<0.05,{ }^{*} P<0.01,{ }^{* *} P<0.001$ compared with control cells. 


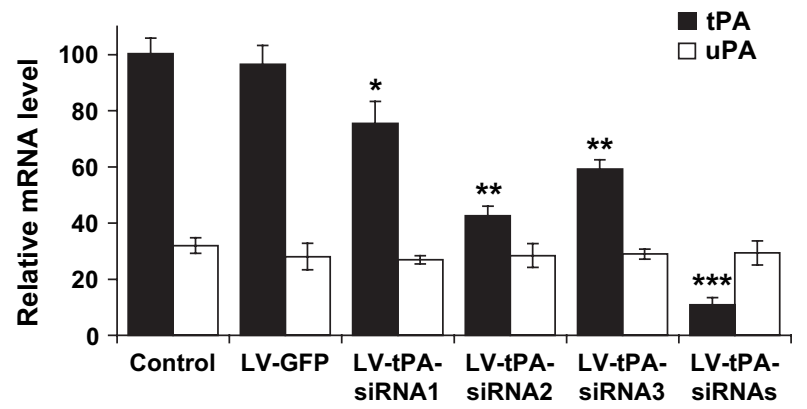

Figure 3: In vitro changes of tPA mRNA expression and inhibition with LV-tPA-siRNAs. HEK293T cells were infected with $3 \mu \mathrm{l}$ of LV-tPA together with $4 \mu \mathrm{l}$ of LV-uPA-His6 alone (control) or together with $2 \mu$ l of LV-GFP (LV-GFP); $2 \mu$ l of LV-tPAsiRNA $1 ; 2 \mu l$ of LV-tPA-siRNA2; $2 \mu$ l of LV-tPA-siRNA3 or all of the LV-tPA-siRNAs together. After $72 \mathrm{~h}$, total RNA was extracted and transcripts were quantified by mean of real-time PCR using specific primers. Values indicate means \pm SEM. ${ }^{*} P<0.05$, ${ }^{*} P<0.01,{ }^{* *} P<0.001$ compared with 'control' cells. after acute cocaine injection $(P<0.05)$. Doxycycline restores locomotor activity back to levels comparable with the GFP controls (Fig. 4A). However, when tPA has been silenced, in treated animals coinfected with LV-tPA-siRNAs - that also silences the endogenously, cocaine-induced tPA - animals show hypolocomotion and locomotor activity decreased to 0.7-fold the activity of the GFP control group $(P<0.05)$; doxycycline had no effects on this group of animals (Fig. 4A). In contrast, when uPA is overexpressed in the NAc while endogenous tPA is silenced, animals show highest locomotor activity, approximately 2.3-fold increase over GFP control group ( $P<0.05$ ), but the effect was completely abolished by downregulation of UPA in the NAc in the same animals fed doxycycline (Fig. 4A). Injection of cocaine on these same animals was continued for 24 days. Then, the animals were submitted to a drug withdrawal period for 2 weeks and finally challenged again with cocaine. Challenge immediately recapitulated locomotor activity observed after acute drug treatment (Fig. 4A'). Locomotor activity directly reflects expression of UPA and tPA in the NAc (see later, Figs 6 and 8).

\section{Effects of amphetamine and morphine}

When animals were expressing tPA in the NAc, locomotor activity after acute amphetamine administration increased
(A)

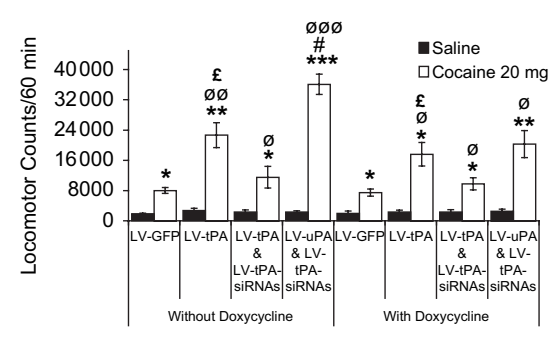

(A')

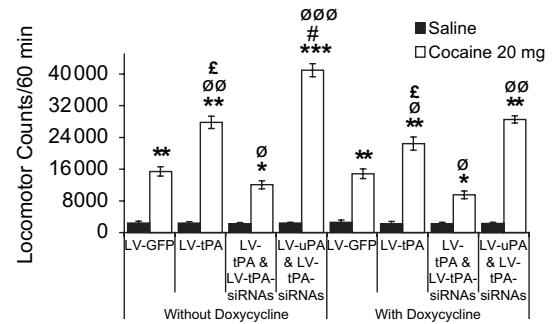

(B)

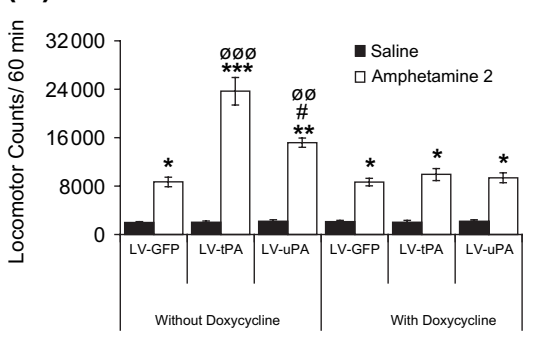

(B')

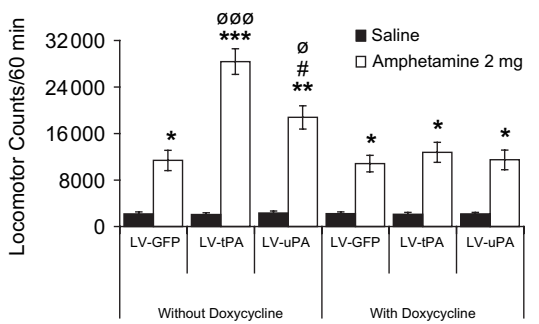

(C)

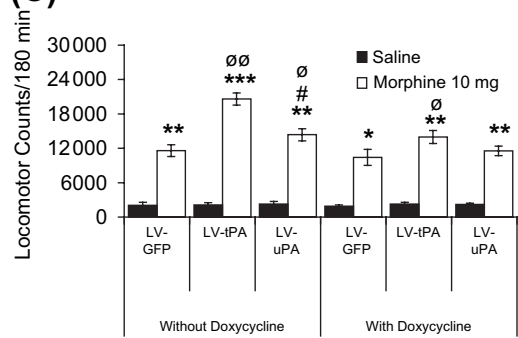

(C')

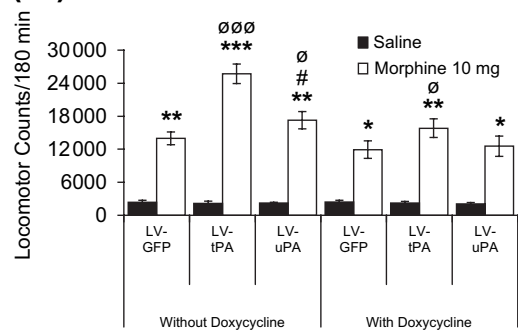

Figure 4: Locomotor stimulating effect of acute cocaine, amphetamine and morphine injections and the locomotor sensitization after single dose challenging with the same drugs. Rats $(n=9)$ were stereotaxically injected with $4 \mu l$ of the indicated lentiviruses; after recovery, open-field locomotor activity was achieved. Upper panels, acute injection: rats were injected saline (1 ml/kg i.p.) and placed in the monitoring cages for $30 \mathrm{~min}$ and injected cocaine (20 mg/kg i.p.) (A), amphetamine (2 mg/kg i.p.) (B) or morphine (10 mg/kg s.c.) (C) and monitored for one more hour ( $3 \mathrm{~h}$ after morphine injection). Lower panels, challenge after withrawal: during 24 consecutive days, rats were injected with the indicated drugs using the same doses as for the acute procedure, followed by a withdrawal period of 2 weeks. After 2 weeks withdrawal, rats were injected saline $(1 \mathrm{ml} / \mathrm{kg}$ i.p.) and then placed in the monitoring cages

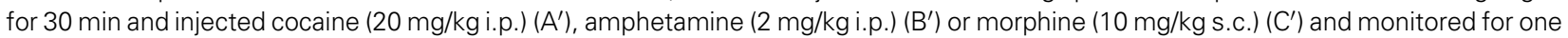
more hour ( $3 \mathrm{~h}$ after morphine injection). For doxycycline regimen, rats $(n=9)$ were fed $0.02 \%$ doxycycline in the drinking water supplemented with $5 \%$ sucrose. Values indicate means \pm SEM. ${ }^{*} P<0.05,{ }^{*} P<0.01,{ }^{*}{ }^{*} P<0.001$ compared with saline-treated animals; ${ }^{\#} P<0.05$ compared with LV-tPA-injected animals; ${ }^{\varnothing} P<0.05$, ${ }^{\varnothing} P<0.01$ compared with LV-GFP-injected animals; ${ }^{\AA} P<0.05$ compared with LV-tPA plus LV-tPA-siRNAs-injected animals. 
4.0-fold, compared with GFP control animals, whereas animals expressing UPA in the NAc show only an approximately 2.2-fold increase in locomotor activity over the GFP control group (Fig. 4B, $P<0.01$ and 0.05 , respectively). Similarly, acute morphine administration induced highest locomotor activity in tPA-treated animals (1.8-fold increase compared with GFP control animals, $P<0.01$ ) over uPA-treated animals (1.3-fold increase compared with GFP control animals, $P<$ 0.05), in sharp contrast to observations made with cocaine administration (Fig. 4C). As above, drug administration on these same animals was continued for 24 days, and then the animals were submitted to a drug withdrawal period for 2 weeks and finally challenged again with the drugs. Challenge immediately recapitulated locomotor activity observed after acute drug treatment (Fig. 4B', $C^{\prime}$ ).

Drug sensitization and effects of gene expression In another experiment (Figs 5 and 6), animals were fed without doxycycline for 10 days, then with doxycycline for 7 days and then again without doxycycline for another 7 days. Drugs were injected daily during these three sessions. Finally, drug was withdrawn for 15 days. At the end of that withdrawal period animals were challenged with a single injection of drug.

Under these conditions, animals show sensitization toward cocaine, which markedly affects locomotor activity (Fig. 5). When UPA is overexpressed in the NAc in presence of LVtPA-siRNAs - that also silence expression of endogenous tPA under cocaine stimulation - locomotor activity is highest, approximately 10 - to 11-fold higher than saline control animals (Fig. 5A'). Under these conditions, tPA-treated animals show lower locomotor activity, approximately 7.5-fold higher than saline controls (days 1-10). In all cases, suppressing tPA or uPA expression in the NAc by doxycycline would suppress the locomotor activity almost down to levels of the control GFP animals (days 11-17), whereas doxycycline removal reinducing $\mathrm{TPA}$ or $\mathrm{UPA}$ expression in the NAC - reinstates the initially observed behavioral effects of the animals (days 1824). Previous studies have shown that doxycycline suppresses uPA mRNA expression and affects uPA protein expression within $24 \mathrm{~h}$, whereas removal of doxycycline reexpresses uPA mRNA and restores protein expression after $24 \mathrm{~h}$ (Bahi et al. 2004a). Animals treated with LV-tPAsiRNAs, - enabling silencing of both endogenous and ectopic tPA - co-injected either with LV-tPA or with LV-uPA showed little sensitization toward cocaine and their behaviors were similar to GFP controls (Fig. 5A').

Amphetamine-treated animals show a sharp drug-induced sensitization. Locomotor activity is markedly stronger when tPA is overexpressed compared with uPA (Fig. 5C'). Tissuetype plasminogen activator induces a 10- to 12-fold increase in locomotor activity, UPA a six- to eightfold, compared with saline treatment. Both effects are doxycycline regulatable in a reversible fashion (Fig. 5B'). In contrast tPA- or UPA-treated animals show no sensitization when administered morphine under chronic paradigm, whether tPA or UPA is overexpressed
(A)

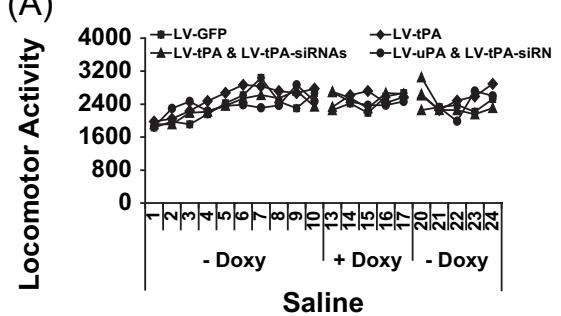

$\left(A^{\prime}\right)$

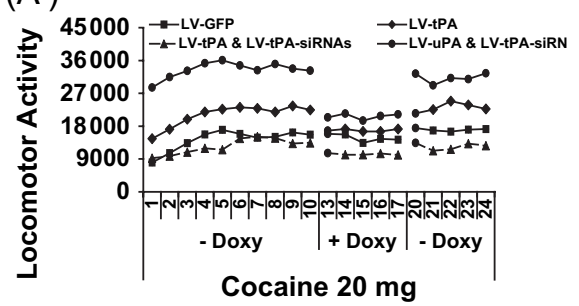

(B)

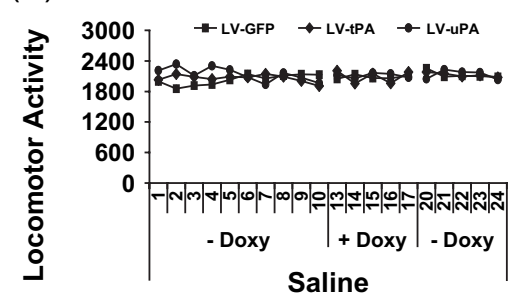

(B')

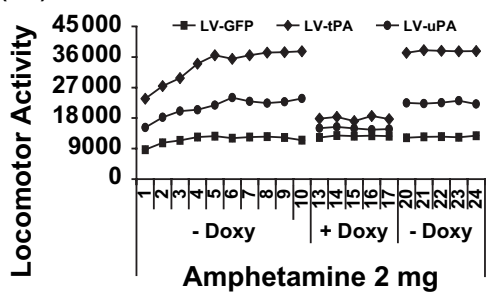

(C)

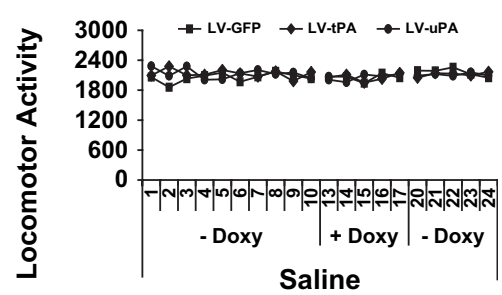

(C')

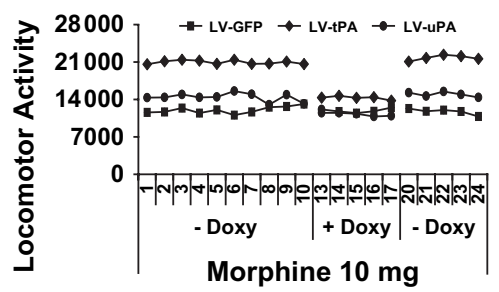

Figure 5: Locomotor stimulating effect of repeated cocaine, amphetamine and morphine injections. Rats $(n=9)$ were stereotaxically injected with $4 \mu$ of the indicated lentiviruses; after recovery, open-field locomotor activity was achieved. Upper panels, effects of saline. Rats were daily injected saline for 24 days ( $1 \mathrm{ml} / \mathrm{kg}$ i.p.) (A, B and C) and placed in the monitoring cages for $30 \mathrm{~min}$. Lower panels, effects of drugs. About $30 \mathrm{~min}$ after saline injections, animals were injected either cocaine (20 mg/kg i.p.) ( $\left.A^{\prime}\right)$, amphetamine (2 $\mathrm{mg} / \mathrm{kg}$ i.p.) (B') or morphine (10 mg/kg s.c.) ( $C^{\prime}$ ) and monitored for one more hour (3 h after morphine injection). Injections were repeated daily. From days 1 to 10, each group of animals was fed water supplemented with $5 \%$ sucrose. The same animals were then switched for 7 days to $0.02 \%$ doxycycline regimen in the drinking water supplemented with $5 \%$ sucrose (from days 11 to 17). Thereafter, animals were switched back to doxycycline-free water for the last 7 days (from days 18 to 24). Values indicate means \pm SEM. Error bars have been omitted from the points for the sake of clarity. 
or whether the exogenous protease is downregulated with doxycycline (Fig. 5C').

\section{Behavioral effects and gene expression}

The NAcs of treated animals were dissected out at the end of series of behavioral measurements and mRNA levels were measured relative to GAPDH. Observed locomotor effects fully correlate with the levels of tPA and uPA mRNA expressed in the different conditions (Fig. 6).
Cocaine administration. Animals treated with tPA showed 2.2-fold higher tPA mRNA expression (compared with GFP control animals, $P<0.05$ ) in acutely injected animals and the ratio remained the same after the challenge (Fig. 6A, $A^{\prime \prime}$ ). Note, however that the level of endogenous tPA increased approximately 1.6-fold under these conditions, from approximately 5.0 in acutely treated GFP animals to approximately 7.8 after challenge, reflecting cocaine-mediated induction of endogenous tPA (Fig. 6A, A"). Animals treated with LV-tPAsiRNAs did not reflect this increase in endogenous tPA upon
(A)

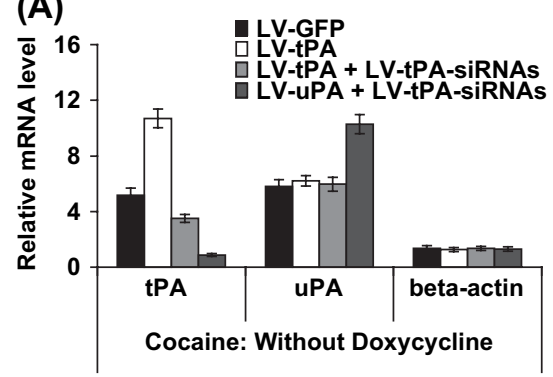

(A')

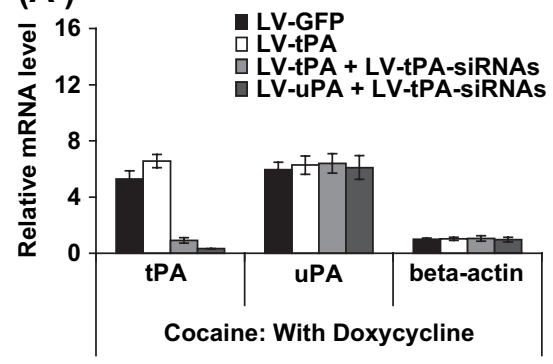

(B)

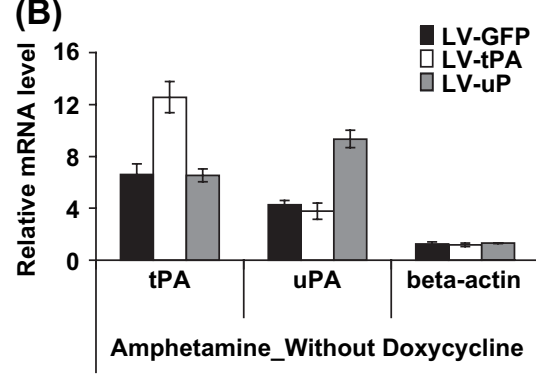

(C)

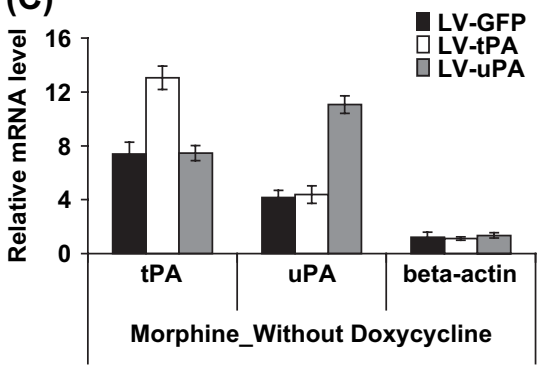

(B')

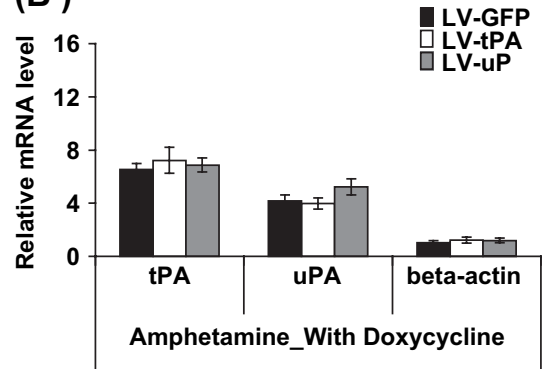

(C')

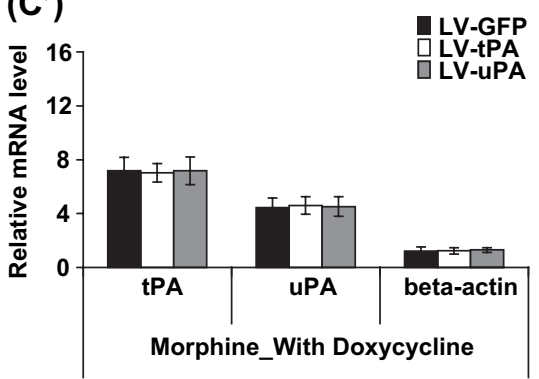

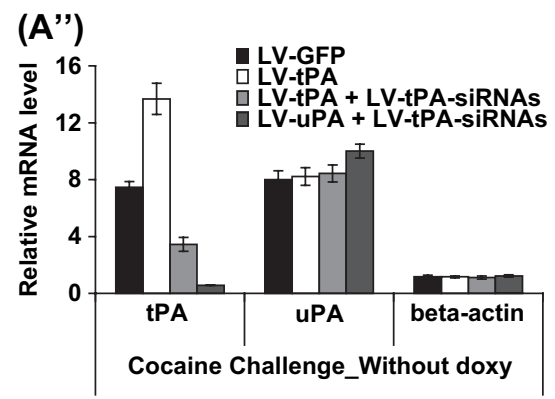

Figure 6: mRNA expression changes of tPA and uPA after repeated cocaine, amphetamine and morphine injections. Rats ( $n=9$ ) were stereotaxically injected with $4 \mu \mathrm{l}$ of the indicated lentiviruses. The NAcs of treated animals were dissected out at the end of series of behavioral measurements and mRNA levels were measured relative to GAPDH. Animals were daily (for 24 days) injected saline $(1 \mathrm{ml} / \mathrm{kg}$ i.p.), placed in the monitoring cages for $60 \mathrm{~min}$ and injected cocaine $\left(20 \mathrm{mg} / \mathrm{kg}\right.$ i.p.) (A, $A^{\prime}$ and $\left.A^{\prime \prime}\right)$, amphetamine (2 mg/kg i.p.) (B and $\left.B^{\prime}\right)$ or morphine (10 mg/kg s.c.) ( $C$ and $C^{\prime}>$ ) and monitored. Upper panels ( $A, B$ and $C$ ): after 10 days some animals were killed, the NAc was dissected out and mRNA prepared for quantitative real-time PCR. Middle panels $\left(A^{\prime}, B^{\prime}\right.$ and $\left.C^{\prime}\right)$ : animals were daily (for 24 days) injected drugs as above. From days 1 to 10, each group of animals was fed water supplemented with $5 \%$ sucrose. Then, animals were switched to $0.02 \%$ doxycycline regimen in the drinking water supplemented with $5 \%$ sucrose for 7 days (from days 11 to 17 ) and then animals were killed, the NAc was dissected out and mRNA prepared for quantitative real-time PCR. Lower panel (A", left): animals were daily (for 24 days) injected drugs as above. From days 1 to 10, each group of animals was fed water supplemented with $5 \%$ sucrose; then, animals were switched to $0.02 \%$ doxycycline regimen in the drinking water supplemented with $5 \%$ sucrose for 7 days. After that period, doxycycline was removed and animals were further injected cocaine for 7 more days and then submitted to a drug withdrawal period for 2 weeks and finally challenged again with cocaine $(20 \mathrm{mg} / \mathrm{kg})$, and killed. The NAc was dissected out and mRNA prepared for quantitative real-time PCR. 
cocaine injection (Fig. 6A, $A^{\prime \prime}$ ). Animals treated with uPA showed 1.8-fold higher UPA mRNA expression (compared with UPA in the GFP control group, $P<0.05$ ) in acutely injected animals (Fig. 6A); this was downregulated to basal level by doxycycline (Fig. 6A'). In all groups, uPA was induced upon cocaine delivery and its endogenous expression in the GFP control group increased from approximately 5.5 after acute injection up to approximately 7.5 after challenge $(P<$ 0.05). Nevertheless, UPA induction in UPA-treated group after challenge was only 1.3-fold higher than in the GFP group, $P<$ 0.05 (Fig. 6A").

Amphetamine and morphine administration. Animals treated with tPA showed 1.8- and 1.9-fold increase in tPA mRNA expression (compared with tPA expression in control groups, $P<0.05)$, after acute administration of amphetamine or morphine, respectively (Fig. 6B, C), whereas in uPA-treated animals the levels of expression were identical to those found in GFP control groups. By contrast, uPA levels of expression after acute amphetamine or morphine administration were identical to levels found in the GFP control groups but were induced 2.5- and 1.9-fold, respectively, in the LV-uPA-treated animals (Fig. 6B, C, $P<0.05$ ). In all cases, doxycycline downregulated tPA or UPA expression back to levels similar to those of the control GFP groups (Fig 6B', $\mathrm{C}^{\prime}$ ).

\section{Gene expression and place preference}

Conditioned place preference was measured on animals infected with the different lentiviruses in the NAc. Animals expressing tPA show a 2.1-fold increase in place preference for cocaine (20 mg/kg; Fig. 7A, $P<0.05$ ). Silencing tPA in the NAc suppressed place preference under these conditions (Fig. 7A). Nevertheless, the observed effects were even much higher with uPA-treated animals, which showed a 3.6-fold increase in cocaine-induced place preference over GFP-treated control animals $(P<0.01$; Fig. 7A). Both amphetamine and morphine induced the opposite effects: injection of $2 \mathrm{mg} / \mathrm{kg}$ amphetamine in tPA-treated animals induced a 2.9- fold increase in place preference over GFP-treated control animals, whereas in UPA-treated animals, amphetamine induced only a 1.9-fold increase in place preference over GFP-treated animals (Fig. 7B, $P<0.01$ and 0.05, respectively). Similarly, injection of $10 \mathrm{mg}$ morphine induced a 3.5fold increase in tPA-treated animals and only a 2.2-fold increase in UPA-treated animals compared with GFP-treated controls (Fig. 7C, $P<0.01$ and 0.05 , respectively). Thus, tPA clearly induces stronger place preference than UPA when amphetamine or morphine is injected, whereas the reverse is observed with cocaine.

To determine whether the observed induction of locomotor activity and drug-induced place preference were correlated with IPA and UPA protein expression, immunohistochemistry was performed using specific His-tag antibodies (Fig. 8). The tPA and UPA proteins were detected in cells of the NAc from either cocaine-, amphetamine- and morphine-treated animals (Fig. 8). No signal was detected in the brain sections of animals co-injected with LV-tPA and LV-tPA-siRNAs following drug administration (Fig. 8D, E, F). However, immunohistochemistry showed that UPA immunoreactivity was highly positive when LV-uPA lentiviral vectors were co-injected with tPA-siRNAs-expressing vectors, supporting the idea that the siRNAs used in this study were highly specific for the knockdown of tPA transcripts and did not affect uPA expression (Fig. 8G, H, I).

To determine whether observed behavioral changes are related to protein expression only or whether the active form of the enzymes are required, the enzymatic activities of tPA and UPA have been determined by SDS-PAGE zymography from tissue extracts after repeated amphetamine and cocaine treatment. Overexpression of tPA and UPA results into enhanced enzymatic activity of these proteases in the NAc (Fig. 9) after repeated injections of cocaine and amphetamine. However, when gene expression of tPA and UPA was inhibited with specific siRNA-expressing lentiviral vectors, no enzymatic activity was observed. We observed also an inhibition of these enzymatic activity when animals were
(A)

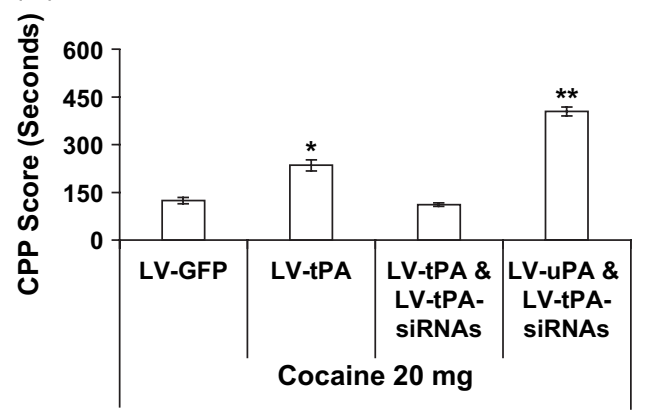

(B)

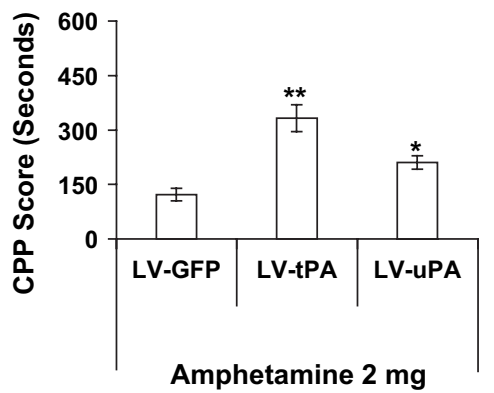

(C)

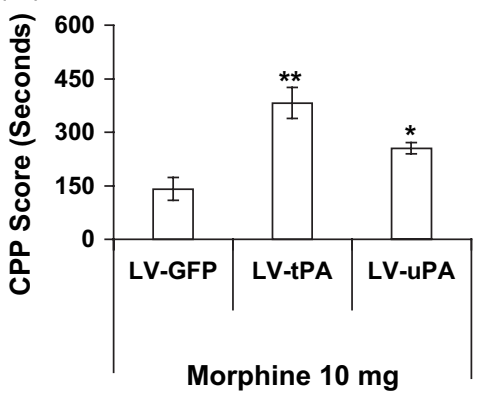

Figure 7: Cocaine-, amphetamine- and morphine-induced place preference in tPA- and uPA-overexpressing animals after stereotaxic injections. Rats $(n=6)$ were stereotaxically injected with $4 \mu$ l of the indicated lentiviruses; after recovery, drugs-induced place preference was achieved. Animals were conditioned using cocaine (20 mg/kg i.p.) (A), amphetamine (2 mg/kg i.p.) (B) or morphine (10 mg/kg s.c.) (C). After 3-day habituation, rats were conditioned using the indicated drugs during the fourth, sixth and eighth days and with saline during the fifth, seventh and ninth days. Rats were then tested for place preference in day 10 without any injection for 20 min. Values indicate means \pm SEM. ${ }^{*} P<0.05,{ }^{*} P<0.01$ compared with LV-GFP-injected animals. 

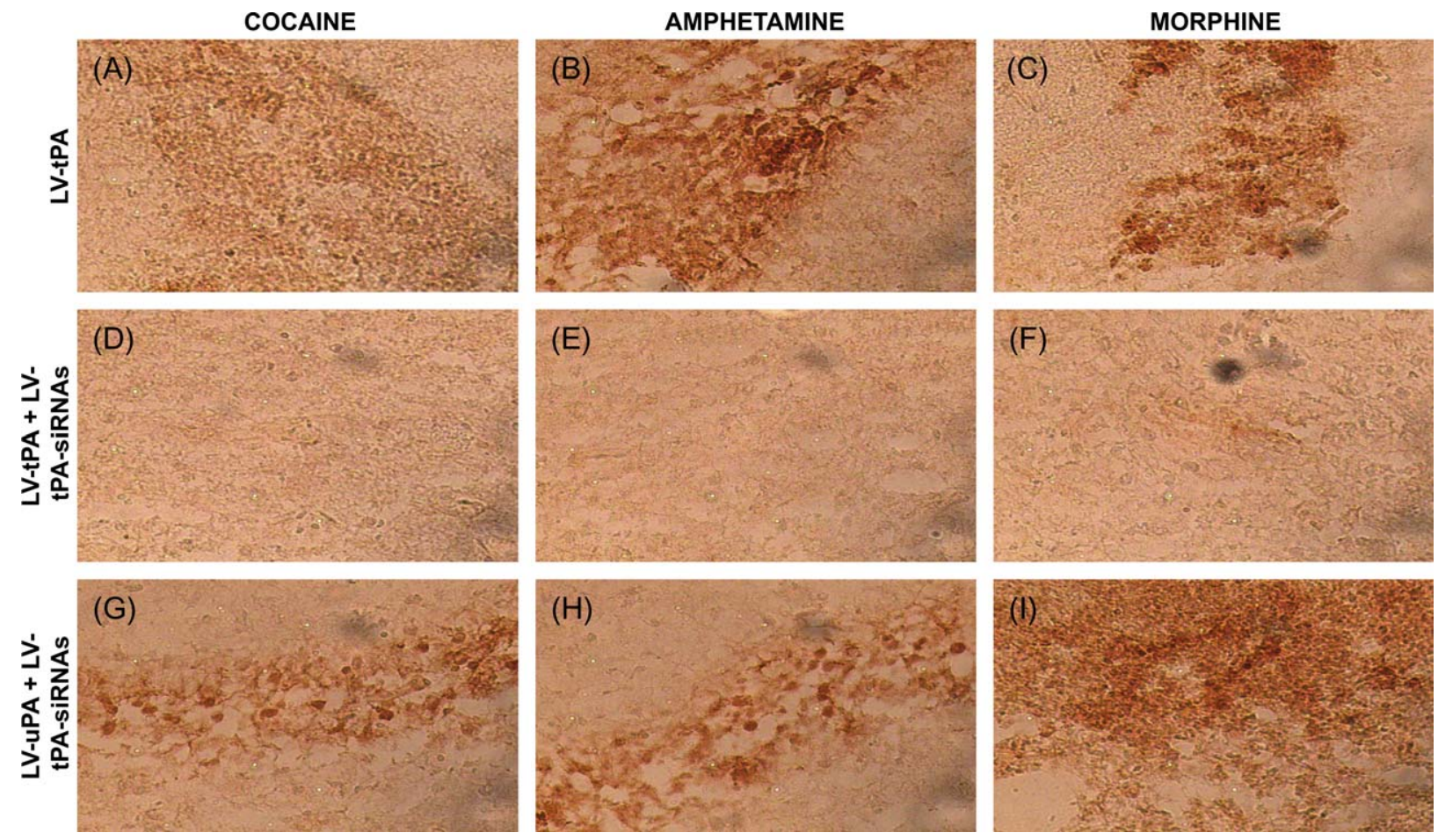

Figure 8: Plasminogen activators (tPA and uPA) immunohistochemistry at the site of stereotaxic injection of LV-tPA or LV-uPA in the NAc. Animals were killed at the end of the experiment; brains were dissected out and processed for immunohistochemistry (see Materials and methods for details). Magnification $\times 40$. Rats were injected with LV-tPA (A, B and C); LV-tPA + LV-tPA-siRNAs (D, E and F) or LV-uPA + LV-tPA-siRNAs (G, H and I). Different groups of rats were treated with cocaine (A, D and $G)$, amphetamine $(B, E$ and $H)$ or morphine (C, F and I).

injected with the mutated form of uPA 'uPA-Mut' where the active site of the protease had been destroyed by sitedirected mutagenesis (Bahi et al. 2004b). Inhibition was also detected when animals infected either with LV-uPA and LVtPA had been fed doxycycline (Fig. 9). This clearly shows that the enzymes are active under normal conditions and suggests that active forms of the enzymes are related to behavioral changes. Furthermore, to check tPA-induced enzymatic activity, animals were injected with LV-tPA together with LVuPA-siRNAs, but, as shown in Fig. 9, uPA-siRNAs, unlike tPAsiRNAs, did not block tPA activity.

\section{Discussion}

Our data show that psychostimulants induce both tPA and UPA in acute and chronic delivery, but cocaine induces preferentially uPA, whereas amphetamine and morphine induce preferentially tPA. Consistent with these findings, animals overexpressing either tPA in the NAc show greater locomotor activity and behavioral sensitization upon morphine or amphetamine treatments, whereas uPA-overexpressing animals show higher activity upon cocaine treatment. These effects could be fully suppressed when tPA or uPA had been silenced or by suppressing ectopic enzyme expression. Furthermore, uPA-overexpressing animals show enhanced conditional place preference for cocaine compared with tPA- overexpressing animals. In contrast, tPA-overexpressing animals showed greater behavioral sensitization and locomotor activity when animals were administered amphetamine or morphine, compared with uPA-overexpressing animals and they showed greater preference for these drugs. Together these, data add further evidence for a significant function of extracellular proteases in addiction and clearly provide evidence for a differential role of plasminogen activators in this context. Clearly, UPA and tPA induce distinct behaviors, which may be interpreted according to their differential pattern of activation.

Plasminogen activators activate the conversion of plasminogen into plasmin, an active extracellular serine protease. The role of plasmin in brain plasticity has been described in development and also in the adult brain. Tissue-type plasminogen activator is involved in synaptic plasticity and remodeling directly by itself, or indirectly by converting plasminogen to plasmin. Tissue-type plasminogen activator is directly involved in long-term potentiation (LTP) by acting on NMDA receptors (Nicole et al. 2001; Shin et al. 2004) and it is induced as an immediate early gene upon stimulation of NMDA receptor (Qian et al. 1993). The tPA secreted in the extracellular space either functions in the extracellular matrix as a protease in synaptic plasticity (Baranes et al. 1998) or binds to its cell surface receptor LRP and activates synaptic potentiation via PKA (Zhuo et al. 2000). Furthermore, tPA is involved in the late phase of long-term potentiation (Baranes 

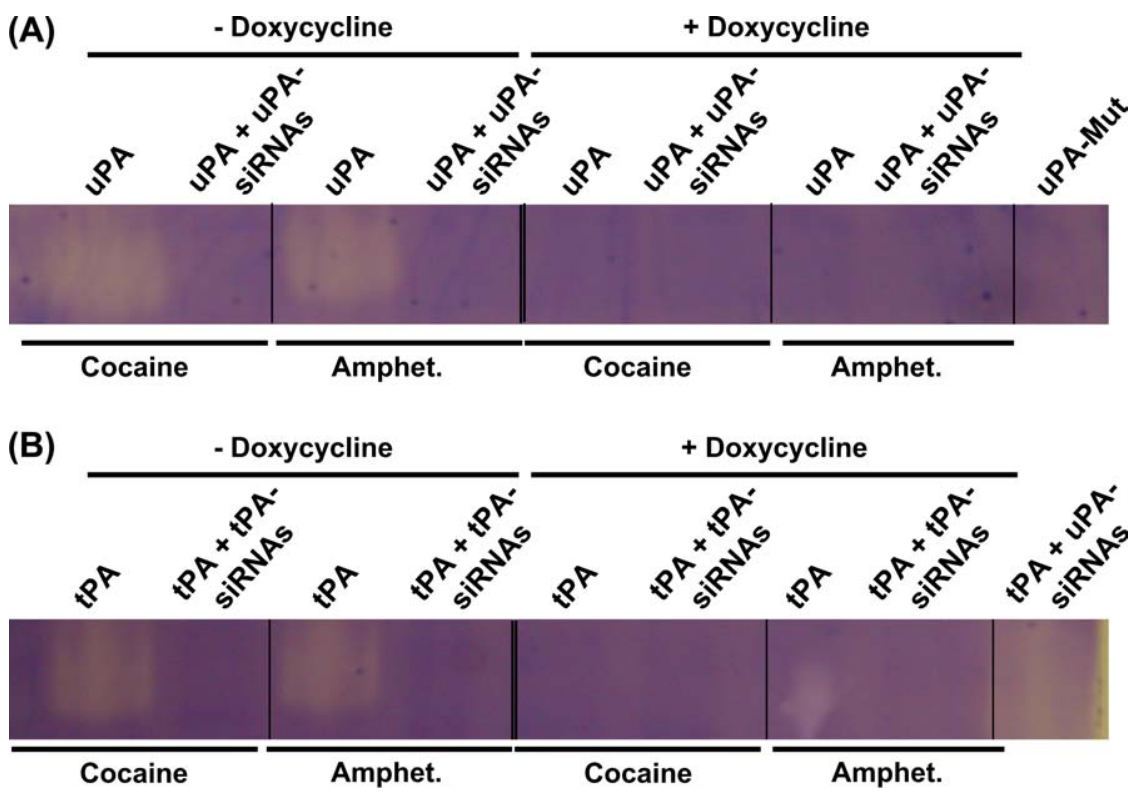

Figure 9: Enzymatic activity of plasminogen activators (tPA and uPA) in the rat brain after stereotaxic injection of LV-uPA (A) or LV-tPA (B) and repeated cocaine and amphetamine treatments measured with SDS-PAGE zymography. Samples were collected from the NAc regions and proteins were extracted as described in Material and methods. Note that uPA and tPA activities were increased both after cocaine and amphetamine treatments. The enzymatic activity was inhibited when LV-tPA-siRNAs, LV-uPA-siRNAs or LV-uPA-Mut was injected or when animals were fed doxycycline in the drinking water. Note that tPA activity was not inhibited with LVuPA-siRNAs indicating that siRNAs-expressing lentiviruses are highly specific.

et al. 1998; Frey et al. 1996), learning and memory (Calabresi et al. 2000; Seeds et al. 1995), excitotoxic neurodegeneration (Siao et al. 2003; Tsirka et al. 1995), and regeneration or recovery from injury in the nervous system (Siconolfi \& Seeds 2001). On the other hand, neurite outgrowth (Krystosek \& Seeds 1981), cell migration (Moonen et al. 1982; Seeds et al. 1999) and tPA-induced amyloid-beta degradation (Melchor et al. 2003; Tucker et al. 2000) are mediated by plasmin. These findings indicate that TPA contributes to the regulation of numerous aspects of synaptic plasticity and remodeling. However, the role of UPA in these different paradigms has not yet been fully described. Furthermore, it is unclear whether the involvement in plasticity of UPA is dependent on plasminrelated modification of extracellular matrix proteins, like tPA.

Exposure to amphetamine produces a long-lasting increase in the length of dendrites and the number of branched spines on medium spiny neurons (Koob \& Nestler 1997; Robinson \& Kolb 1997). Morphine increases dopaminergic neurotransmission in the NAc via the activation of dopamine cells in the VTA, an area that possesses a high density of m-opioid receptors. This activation results mainly from the disinhibition of inhibitory GABAergic interneurons in the VTA (Bonci \& Williams 1997; Johnson \& North 1992). Because synaptic plasticity is strongly activated by psychostimulants and may be a cause for long-term adaptive changes, it is reasonable to assume that active plasmin plays a central function in addiction. Indeed, the tPA-plasmin system plays an important role in the rewarding and locomotor-stimulating effects of morphine by regulating morphine-induced dopamine release in the NAc (Nagai et al. 2004). Morphine treatment increases not only tPA in the NAc but also inhibitor-1 of plasminogen activator (PAI-1), a serine protease inhibitor that regulates plasminogen activation (Nagai et al. 2005a). Similarly, repeated methamphetamine treatment induces tPA expression in the frontal cortex, NAc, striatum and hippocampus, whereas single methamphetamine treatment does not affect tPA expression. In respect to cocaine, tPA knockout mice show cocaine-induced locomotor activity at lower doses than wild-type control mice and a greater degree of cocaineinduced locomotor activity following repeated administration (Ripley et al. 1999). Nevertheless, tPA knockout mice did not show facilitation of acquisition of cocaine self-administration, whereas the effects of behavioral sensitization in tPA knockout mice were reversed by microinjections of exogenous tPA into the NAc (Ripley et al. 1999).

Our study show that UPA and tPA respond very differently to psychostimulants. In agreement with findings by Nagai et al. (2004, 2005b), we found that tPA overexpression enhances amphetamine and morphine behavioral sensitization. With cocaine, however, according to Ripley et al. (1999), tPA knockout mice are not sensitized when tPA is absent and, if recombinant tPA is given back, they show a conditioned place preference score almost identical to wild-type mice; furthermore, at low doses of cocaine, tPA knockout mice showed enhanced locomotor activity when compared with their wild-type littermates and show increased behavioral sensitization than wild type (Ripley et al. 1999). Therefore, one would reasonably assume that if these mice were injected with our LV-tPA, they would show less locomotor activity to cocaine and less behavioral sensitization, which is 
strikingly in contrast to our observations. Nevertheless, developmental compensatory mechanisms cannot be excluded in these processes and it is possible that UPA or other matrix proteases can take over the function of tPA in tPA knockout mice. Rescue experiments are planed with these mice to settle this controversy.

On the other hand, the gene encoding tPA is regulated in a cell-type-specific manner by a complex array of transcription factors that include Sp-1, AP-2, tPACRE and CREB (Costa et al. 2004). The specific roles of these transcription factors in addiction remain to be described in more details to better characterize the regulation of plasminogen activators in this paradigm. Changes in tPA (and UPA) mRNA expression in the brain reward pathway after repeated drug treatments may be due at least in part to the alteration in the ratios of these transcription factors. It is well established that CREB levels are changed in the NAc after chronic drug treatments (Widnell et al. 1996).

The tPA- and uPA-plasmin systems degrade several extracellular matrix proteins (Schnaper 1995), including laminin (Goldfinger et al. 2000). Laminin in the synaptic cleft localizes calcium channels to the sites of active zones (Sunderland et al. 2000) and may induce significant increase in calcium levels (Bixby et al. 1994). Accordingly, it is possible that psychostimulant-mediated induction of the tPA-plasmin system may result in a malfunction of calcium channel activity, leading to the reduction of dopamine release, because the tPA-plasmin system is involved in the regulation of dopamine release in the NAc (lto et al. 2006). Activation of the tPA-plasmin system stimulates protease-activated receptor-1 (PAR1; Kuliopulos et al. 1999), which in turn increases intracellular calcium mobilization, leading to a potentiation of depolarization-evoked dopamine release in the NAc (Dery et al. 1998). Microinjection of either tPA or plasmin significantly potentiates dopamine release without affecting basal dopamine levels (Ito et al. 2006). Dopamine release in the NAc was markedly diminished in IPA knockout mice compared with wild type, whereas microinjections of either exogenous tPA or plasmin into the NAc of tPA knockout mice restored dopamine release as observed in wild-type mice (Ito et al. 2006). Furthermore, microinjection of a PAR1 antagonist, [tyr(-1)]thrombin receptor activating peptide 7 , into the NAc significantly reduced morphine-induced dopamine release in the $\mathrm{NAc}$ and hyperlocomotion although the treatment had no effect on basal dopamine release and spontaneous locomotor activity, suggesting that PAR1 is a target for the tPAplasmin system in the regulation of acute morphine-induced dopamine release in the NAc (Ito et al. 2007).

Another pathway is also very relevant to drug-mediated tPA and UPA expression. It has been shown that plasmin converts the precursor pro-brain-derived neurotrophic factor (BDNF) to mature BDNF in vitro and that this conversion is critical for the expression of late-phase LTP in the mouse hippocampus (Pang et al. 2004). Most of BDNF secreted by neurons appears to be in the precursor form and the secretion of pro-BDNF is activity dependent (Chen et al. 2004). Brainderived neurotrophic factor is released upon neuronal depolarization and triggers rapid intracellular signaling and action potentials in neurons (Poo 2001), because BDNF promotes the depolarization-evoked release of dopamine from mesencephalic neurons (Blochl \& Sirrenberg 1996). Therefore, the tPA- and uPA-plasmin system, through the maturation of BDNF, may regulate BDNF-mediated depolarization-evoked dopamine release. Potentiation of excitatory synapses triggers the release of glutamate, followed by evoked expression of BDNF, which stimulates the expression and activation of the proteolytic activity of plasminogen activators, tPA and uPA. Either directly or indirectly via plasmin formation, this system may act to cleave extracellular matrix molecules or cell adhesion molecules, allowing structural changes associated with neuronal development or synaptic plasticity. Thus, the neurotrophic activity by BDNF may manipulate longlasting structural plasticity through tPA. It is well established that BDNF, administered directly into the VTA or NAc, causes a profound increase in cocaine-induced locomotor activity and in cocaine reward in several behavioral paradigms (Hall et al. 2003; Horger et al. 1999).

Our study shows that UPA and tPA respond very differently to psychostimulants. We found that tPA overexpression enhances cocaine, amphetamine and morphine behavioral sensitization, which is in agreement with findings by Nagai et al. $(2004,2005 b)$ concerning amphetamine and morphine in tPA knockout mice. According to their data, tPA knockout mice are not sensitized when tPA is absent, but if recombinant tPA is given back, they show a conditioned place preference score almost identical to wild-type mice.

Furthermore, our data suggest that the active forms of the enzymes are required for drug sensitization. Nevertheless additional studies, using dominant inactive constructs will be needed. As a matter of fact, both the active and the inactive forms of UPA may bind to its receptor UPAR and the complexes may activate cellular transduction and intracellular cytoskeletal arrangement. Similarly, the inactive and the active forms of tPA bind different extracellular matrix molecules. In addition, UPA appears to have protein-binding characters different from tPA, because tPA but not uPA binds fibrin.

Our findings raise several questions that cannot be fully answered yet. Further studies will be required to determine at which stage of addiction the genes are involved and whether they are involved in the acquisition/learning phase or in the expression/retrieval phase of drug preference. In addition, psychostimulants induce a large cluster of gene expression changes in the mesolimbic pathway. It is therefore well possible that the observed differential behaviors may be correlated with drug-mediated coexpression of several other specific partners, either of UPA or of tPA, for example, uPAR, PAI-1, PAI-2, PAR1, and so forth, besides components of several intracellular signal transduction cascades. The identification of these partners will be important for elucidation of the different mechanisms. Nevertheless, the observed differences may be of pharmacological relevance. We have shown that inhibition of uPA by B428, a highly specific uPA inhibitor, fully blocks cocaine-mediated locomotor activity (Bahi et al. 2006). A similar tPA-specific inhibitor would be highly useful to prevent amphetamine and morphine reward. Therefore, this study opens new paths to better understanding the molecular basis of addiction and possibly toward its treatment. 
We found that tPA and UPA expression is not much affected by a single injection of cocaine but is highly induced after multiple injections. Behavioral sensitization in turn results from multiple molecular changes and structural synaptic adaptations, affecting dendritic length and spine density. We propose that plasminogen activators may play an important role in these structural adaptations, in view of their effects on extracellular matrix degradation (plasmin, laminin) and on metalloproteases activation at the surface of the neurons. Thus, tPA and uPA will induce long-lasting effects, affecting structural changes leading to synaptic plasticity and therefore to drug dependence.

\section{References}

Bahi, A. \& Dreyer, J.L. (2005) Cocaine-induced expression changes of axon guidance molecules in the adult rat brain. Mol Cell Neurosci 28, 275-291.

Bahi, A., Boyer, F., Gumy, C., Kafri, T. \& Dreyer, J.L. (2004a) In vivo gene delivery of urokinase-type plasminogen activator with regulatable lentivirus induces behavioural changes in chronic cocaine administration. Eur J Neurosci 20, 3473-3488.

Bahi, A., Boyer, F., Kafri, T. \& Dreyer, J.L. (2004b) CD81-induced behavioural changes during chronic cocaine administration: in vivo gene delivery with regulatable lentivirus. Eur J Neurosci 19, 1621-1633.

Bahi, A., Boyer, F., Bussard, G. \& Dreyer, J.L. (2005a) Silencing dopamine D3-receptors in the nucleus accumbens shell in vivo induces changes in cocaine-induced hyperlocomotion. Eur J Neurosci 2112, 3415-3426.

Bahi, A., Boyer, F., Kolira, M. \& Dreyer, J.L. (2005b) In vivo gene silencing of CD81 by lentiviral expression of small interference RNAs suppresses cocaine-induced behaviour. J Neurochem $\mathbf{9 2}$, 1243-1255.

Bahi, A., Boyer, F., Kafri, T. \& Dreyer, J.L. (2006) Silencing urokinase in the ventral tegmental area in vivo induces changes in cocaineinduced hyperlocomotion. J Neurochem 98, 1619-1631.

Baranes, D., Lederfein, D., Huang, Y.Y., Chen, M., Bailey, C.H. \& Kandel, E.R. (1998) Tissue plasminogen activator contributes to the late phase of LTP and to synaptic growth in the hippocampal mossy fiber pathway. Neuron 21, 813-825.

Bixby, J.L., Grunwald, G.B. \& Bookman, R.J. (1994) Calcium influx and neurite growth in response to purified $\mathrm{N}$-cadherin and laminin. $J$ Cell Biol 127, 1461-1475.

Blochl, A. \& Sirrenberg, C. (1996) Neurotrophins stimulate the release of dopamine from rat mesencephalic neurons via Trk and p75Lntr receptors. J Biol Chem 271, 21100-21107.

Bonci, A. \& Williams, J.T. (1997) Increased probability of GABA release during withdrawal from morphine. J Neurosci 17 796-803.

Bu, G., Maksymovitch, E.A., Geuze, H. \& Schwartz, A.L. (1994) Subcellular localization and endocytic function of low density lipoprotein receptor-related protein in human glioblastoma cells. J Biol Chem 269, 29874-29882.

Calabresi, P., Napolitano, M., Centonze, D. et al. (2000) Tissue plasminogen activator controls multiple forms of synaptic plasticity and memory. Eur J Neurosci 12, 1002-1012.

Chen, Z.Y., Patel, P.D., Sant, G., Meng, C.X., Teng, K.K., Hempstead, B.L. \& Lee, F.S. (2004) Variant brain-derived neurotrophic factor (BDNF) (Met66) alters the intracellular trafficking and activitydependent secretion of wild-type BDNF in neurosecretory cells and cortical neurons. J Neurosci $24,4401-4411$.

Costa, M., Shen, Y., Maurer, F. \& Medcalf, R.L. (1998) Transcriptional regulation of the tissue-type plasminogen-activator gene in human endothelial cells: identification of nuclear factors that recognise functional elements in the tissue-type plasminogen-activator gene promoter. Eur J Biochem 258, 123-131.

Davies, B.J., Pickard, B.S., Steel, M., Morris, R.G. \& Lathe, R. (1998) Serine proteases in rodent hippocampus. J Biol Chem 273, 23004-23011.
Dery, O., Corvera, C.U., Steinhoff, M. \& Bunnett, N.W. (1998) Proteinase-activated receptors: novel mechanisms of signaling by serine proteases. Am J Physiol 274, C1429-C1452.

Frey, U., Muller, M. \& Kuhl, D.A. (1996) Different form of long-lasting potentiation revealed in tissue plasminogen activator mutant mice. J Neurosci 16, 2057-2063.

Goldfinger, L.E., Jiang, L., Hopkinson, S.B., Stack, M.S. \& Jones, J.C. (2000) Spatial regulation and activity modulation of plasmin by high affinity binding to the $\mathrm{G}$ domain of the alpha-3 subunit of laminin-5. J Biol Chem 275, 34887-34893.

Hall, F.S., Drgonova, J., Goeb, M. \& Uhl, G.R. (2003) Reduced behavioral effects of cocaine in heterozygous brain-derived neurotrophic factor (BDNF) knockout mice. Neuropsychopharmacology 28, 1485-1490.

Hayden, S.M. \& Seeds, N.W. (1996) Modulated expression of plasminogen activator system components in cultured cells from dissociated mouse dorsal root ganglia. J Neurosci 16, 2307-2317.

Horger, B.A., lyasere, C.A., Berhow, M.T., Messer, C.J., Nestler, E.J. \& Taylor, J.R. (1999) Enhancement of locomotor activity and conditioned reward to cocaine by brain-derived neurotrophic factor. J Neurosci 19, 4110-4122.

Ito, M., Nagai, T., Kamei, H., Nakamichi, N., Nabeshima, T., Takuma, K. \& Yamada, K. (2006) Involvement of tissue plasminogen activator-plasmin system in depolarization-evoked dopamine release in the nucleus accumbens of mice. Mol Pharmacol 70 1720-1725.

Ito, M., Nagai, T., Mizoguchi, H., Fukakusa, A., Nakanishi, Y., Kamei, H., Nabeshima, T., Takuma, K. \& Yamada, K. (2007) Possible involvement of protease-activated receptor- 1 in the regulation of morphine-induced dopamine release and hyperlocomotion by the tissue plasminogen activator-plasmin system. J Neurochem 101 1392-1399.

Jacovina, A.T., Zhong, F., Khazanova, E., Lev, E., Deora, A.B. \& Hajjar, K.A. (2001) Neuritogenesis and the nerve growth factor-induced differentiation of PC-12 cells requires annexin II-mediated plasmin generation. J Biol Chem 276, 49350-49358.

Johnson, S.W. \& North, R.A. (1992) Opioids excite dopamine neurons by hyperpolarization of local interneurons. J Neurosci 12, 483-488.

Koob, G.F. \& Nestler, E.J. (1997) The neurobiology of drug addiction. J Neuropsychiat Clin Neurosci 9, 482-497.

Kuliopulos, A., Covic, L., Seeley, S.K., Sheridan, P.J., Helin, J. \& Costello, C.E. (1999) Plasmin desensitization of the PAR1 thrombin receptor: kinetics, sites of truncation, and implications for thrombolytic therapy. Biochemistry 38, 4572-4585.

Krystosek, A. \& Seeds, N.W. (1981) Plasminogen activator release at the neuronal growth cone. Science 213, 1532-1534.

Meiri, N., Masos, T., Rosenblum, K., Miskin, R. \& Dudai, Y. (1994) Overexpression of urokinase-type plasminogen activator in transgenic mice is correlated with impaired learning. Proc Natl Acad Sci U S A 91, 3196-3200.

Melchor, J.P., Pawlak, R. \& Strickland, S. (2003) The tissue plasminogen activator-plasminogen proteolytic cascade accelerates amyloid- $\beta$ (Ab) degradation and inhibits $A b$-induced neurodegeneration. J Neurosci 23, 8867-8871.

Moonen, G., Grau-Wagemans, M.P. \& Selak, I. (1982) Plasminogen activator-plasmin system and neuronal migration. Nature 298 753-755.

Nagai, T., Yamada, K., Yoshimura, M., Ishikawa, K., Miyamoto, Y., Hashimoto, K., Noda, Y., Nitta, A. \& Nabeshima, T. (2004) The tissue plasminogen activator-plasmin system participates in the rewarding effect of morphine by regulating dopamine release. Proc Natl Acad Sci U S A 101, 3650-3655

Nagai, T., Kamei, H., Ito, M., Hashimoto, K., Takuma, K., Nabeshima, T. \& Yamada, K. (2005a) Modification by the tissue plasminogen activator-plasmin system of morphine-induced dopamine release and hyperlocomotion, but not anti-nociceptive effect in mice. J Neurochem 93, 1272-1279.

Nagai, T., Noda, Y., Ishikawa, K., Miyamoto, Y., Yoshimura, M., Ito, M., Takayanagi, M., Takuma, K., Yamada, K. \& Nabeshima, T. (2005b) The role of tissue plasminogen activator in methamphetamine related reward and sensitization. J Neurochem $\mathbf{9 2}$,660-667.

Nakagami, Y., Abe, K., Nishiyama, N. \& Matsuki, N. (2000) Laminin degradation by plasmin regulates long-term potentiation. J Neurosci 20. 2003-2010. 
Nestler, E.J. (2001) Molecular basis of long-term plasticity underlying addiction. Nat Rev Neurosci 2, 119-128.

Nicole, O., Docagne, F., Ali, C., Margaill, I., Carmeliet, P., MacKenzie, E.T., Vivien, D. \& Buisson, A. (2001) The proteolytic activity of tissue-plasminogen activator enhances NMDA receptor-mediated signaling. Nat Med 7, 59-64.

Pang, P.T., Teng, H.K., Zaitsev, E., Woo, N.T., Sakata, K., Zhen, S., Teng, K.K., Yung, W.H., Hempstead, B.L. \& Lu, B. (2004) Cleavage of proBDNF by tPA/plasmin is essential for long-term hippocampal plasticity. Science 306, 487-491.

Paxinos, G. \& Watson, C. (1998) The Rat Brain in Stereotaxic Coordinates, 4th edn. Academic Press, San Diego, CA.

Poo, M.M. (2001) Neurotrophins as synaptic modulators. Nat Rev Neurosci 2, 24-32.

Qian, Z., Gilbert, M.E., Colicos, M.A., Kandel, E.R. \& Kuhl, D. (1993) Tissue-plasminogen activator is induced as an immediate-early gene during seizure, kindling and long-term potentiation. Nature 361, 453-457.

Ripley, T.L., Rocha, B.A., Oglesby, M.W. \& Stephens, D.N. (1999) Increased sensitivity to cocaine, and over-responding during cocaine self-administration in tPA knockout mice. Brain Res $\mathbf{8 2 6}$, $117-127$.

Robinson, T.E. \& Kolb, B. (1997) Persistent structural modifications in nucleus accumbens and prefrontal cortex neurons produced by previous experience with amphetamine. J Neurosci 17, 8491-8497.

Sappino, A.P., Madani, R., Huarte, J., Belin, D., Kiss, J.Z., Wohlwend, A. \& Vassalli, J.D. (1993) Extracellular proteolysis in the adult murine brain. J Clin Invest 92, 679-685.

Schenk, S. \& Snow, S. (1994) Sensitization to cocaine's motor activating properties produced by electrical kindling of the medial prefrontal cortex but not of the hippocampus. Brain Res 659 , $17-22$.

Schnaper, H.W. (1995) Balance between matrix synthesis and degradation: a determinant of glomerulosclerosis. Pediatr Nephrol 9, 104-111.

Seeds, N.W., Williams, B.L. \& Bickford, P.C. (1995) Tissue plasminogen activator induction in Purkinje neurons after cerebellar motor learning. Science 270, 1992-1994.

Seeds, N.W., Basham, M.E. \& Haffke, S.P. (1999) Neuronal migration is retarded in mice lacking the tissue plasminogen activator gene. Proc Natl Acad Sci U S A 96, 14118-14123.

Siao, C.J., Fernandez, S.R. \& Tsirka, S.E. (2003) Cell type-specific roles for tissue plasminogen activator released by neurons or microglia after excitotoxic injury. J Neurosci 23, 3234-3242.
Siconolfi, L.B. \& Seeds, N.W. (2001) Induction of the plasminogen activator system accompanies peripheral nerve regeneration after sciatic nerve crush. J Neurosci 21, 4336-4347.

Shin, C.Y., Kundel, M. \& Wells, D.G. (2004) Rapid, activity-induced increase in tissue plasminogen activator is mediated by metabotropic glutamate receptor-dependent mRNA translation. J Neurosci 24, 9425-9433.

Sunderland, W.J., Son, Y.J., Miner, J.H., Sanes, J.R. \& Carlson, S.S. (2000) The presynaptic calcium channel is part of a transmembrane complex linking a synaptic laminin $(\alpha 4 \beta 2 \gamma 1)$ with non-erythroid spectrin. J Neurosci 20, 1009-1019.

Tsirka, S.E., Gualandris, A., Amaral, D.G. \& Strickland, S. (1995) Excitotoxin-induced neuronal degeneration and seizure are mediated by tissue plasminogen activator. Nature 377, 340-344.

Tucker, H.M., Kihiko, M., Caldwell, J.N. et al. (2000) The plasmin system is induced by and degrades amyloid- $\beta$ aggregates. J Neurosci 20, 3937-3946.

Widnell, K.L., Self, D.W., Lane, S.B., Russell, D.S., Vaidya, V.A., Miserendino, M.J., Rubin, C.S., Duman, R.S. \& Nestler, E.J. (1996) Regulation of CREB expression: in vivo evidence for a functional role in morphine action in the nucleus accumbens. J Pharmacol Exp Ther 276, 306-315.

Zhuo, M., Holtzman, D.M., Li, Y., Osaka, H., DeMaro, J., Jacquin, M. \& Bu, G. (2000) Role of tissue plasminogen activator receptor LRP in hippocampal long-term potentiation. J Neurosci 20, 542-549.

Wu, Y.P., Siao, C.J., Lu, W., Sung, T.C., Frohman, M.A., Milev, P., Bugge, T.H., Degen, J.L., Levine, J.M., Margolis, R.U. \& Tsirka, S.E. (2000) The tissue plasminogen activator (tPA)/plasmin extracellular proteolytic system regulates seizure-induced hippocampal mossy fiber outgrowth through a proteoglycan substrate. J Cell Biol 148, 1295-1304.

\section{Acknowledgments}

This work was supported by Swiss National Foundation grants 3100-059350 and 3100AO-100686 (J.L.D.). We thank Dr Alexander Kusnecov (Rutgers University, USA) for the critical reading of the manuscript, helpful comments and advices. We are also very grateful to J.-P. Gabriel, C. Mazza, T. Fournier and J. Pasquier (Mathematics Department, Fribourg) for their assistance in the statistical analysis, and Frederic Boyer, Vijay Chandrasekar, Christel Gumy and Christine Deforel-Poncet for skilful technical assistance. 